\title{
Curriculum Reformation of University of Applied Sciences in the Big Data Era in China
}

\author{
Xu Chengying ${ }^{1}$, Wang Yaping ${ }^{1}$, Wang Minghao ${ }^{2}$ \\ ${ }^{1}$ Teaching Affairs Department, Tianjin Sino-German University of Applied Sciences, Tianjin, China \\ ${ }^{2}$ School of Aeronautics and Astronautics, Tianjin Sino-German University of Applied Sciences, Tianjin, China \\ Email address: \\ tjafz@126.com (Xu Chengying),willbrightman@126.com (Wang Yaping)
}

To cite this article:

Xu Chengying, Wang Yaping, Wang Minghao. Curriculum Reformation of University of Applied Sciences in the Big Data Era in China. Education Journal. Vol. 8, No. 5, 2019, pp. 168-174. doi: 10.11648/j.edu.20190805.11

Received: June 17, 2019; Accepted: July 22, 2019; Published: August 8, 2019

\begin{abstract}
Higher education is facing many emerging challenges in the big data era, curriculum has to be reconstructed with big data technologies to get teaching and learning better and better, cause big data technologies has the abilities to mining magnanimity data produced and predict the important parts in the education process. Curriculum of university of applied sciences is a new type vocational and educational course in higher education, birth in the big date era, must be constructed with big data technologies, such as data mining, statistical analysis, mathematic model, cloud computing. Tianjin Sino-German University of Applied Sciences, the first university of applied sciences in Mainland China, deployed big data technologies including date collection, data storage, data analysis, and data visualization to it's curriculum reform, reforming links with curriculum design, curriculum development, curriculum implementation and curriculum evaluation, constructing a Dual Curriculum System is characterized by Chinese universities of applied sciences, resolving various contradictions and problems in the development of university of applied sciences. The curriculum reformation advances the process of constructing course, and improve the output of teaching and learning. Nevertheless, we found the big data talents is not sufficient, and the big data facilities cannot meet high quality of operation demand, these insufficient factors must be solved to make the dual curriculum system perfect. Moreover, Tianjin Sino-German University of Applied Science's curriculum reformation can be provided useful experience and lessons for many other universities of applied science, also can be reference for international universities of applied sciences.
\end{abstract}

Keywords: The Big Data Era, University of Applied Sciences, Dual Curriculum System

\section{Introduction}

"Big data is a collection of data with large capacity, multiple types, fast access speed and high application value. It is rapidly developing to collect, store and correlate data with a large number of sources, scattered sources and diverse formats, discover new knowledge and create new value, promote new ability of a new generation of information technology and services business"[1]. On August 31, 2015, the State Council issued the Outline for the Promotion of Big Data Development; on October 21, 2015, the Ministry of Education issued the Ministry of Education, National Development and Reform Commission, Ministry of Finance, issued a guidance on guiding the transformation of some local undergraduate colleges and universities into application-oriented. "Big Data is a fast-growing phenomenon which has already become pervasive across a number of sectors - health, business and government. As a new field of inquiry in higher education, it incorporates research areas such as Educational Data Mining (EDM) and learning analytics. "[2] University of applied sciences emphasizes the accumulation, research, development and inheritance of technology. As a new-type University of Chinese higher education system, large data provides a new perspective for the construction of University of Applied Sciences. 


\section{Background of Curriculum Reformation of Universities of Applied Sciences}

University of Applied Sciences began in Europe, the German University of Applied Sciences is typical, is designed to serve local economic development of the new institutions of higher learning occurs in the era of mass higher education. In the context of a changing global landscape and the development of new technologies, universities have complex challenges. [3] Outline of the National Education Medium- and Long-Term Planning Development proposes to base on the national conditions, grasp the stage characteristics of education development, adhere to the people-oriented principle, follow the law of education, and meet the needs of society, establish a classification system for colleges and universities, implement classified management, and focus on expanding the scale of application, compound and technical talents. The Ministry of Education has clearly proposed to promote the transformation of colleges and universities, so that the educational goals and quality standards of the transitional universities will better meet the needs of the society and be more in line with the school-running orientation of applied universities. In the same year, the Ministry of Education agreed to establish Tianjin Sino-German University of Applied Sciences and gave it the mission of "exploring and building an applied sciences university, developing characteristics, and achieving a level of contribution to make greater contributions to Tianjin's economic development and social progress".

"The curriculum is a program to achieve the goal of talent training", The construction of the curriculum system is the first problem to be solved by the applied sciences university. "Big data has subverted the way humans explore and recognize the world, opening a door to education".[4] The Applied Sciences University Course is a large collection of data, including student learning background, learning process, learning outcomes, teacher's knowledge background, teaching process, teaching outcomes, industry knowledge background, development status and future trends, job capacity needs, development needs, etc., big data technology provides support for the construction of the curriculum system of the University of Applied Sciences.

\section{Problems Facing the Reformation of Applied Sciences Universities}

There are many application-based curriculum models, such as CDIO mode - Conceive, Design, Implement and Operate, Problem-Based Learning mode, "Platform + Module" course mode, etc. However, they all have a certain distance from the development needs of Industry 4. 0. The goal of talents training in applied sciences universities is to cultivate the application-oriented and technical-skilled talents needed by the regional economy and society. How to take root in
China's land to run a university with Chinese characteristics is also facing a series of problems.

\subsection{Lack of Experienced Teachers in the Course Construction of the University of Applied Sciences}

'It is widely recognized that the teacher is the most significant factor to impact the quality of students' learning experience and outcomes' [5]. The Applied Sciences University Program is a new curriculum that is either a heritage of existing higher vocational and local undergraduate courses or a evolution to existing ones. Especially the great changes in talent training objectives occurred. If the destination changes, the conductor of the four locomotives which contain the course design, development, implementation and evaluation must reschedule. At present, there is no institution that specializes in cultivating university teachers of applied sciences, and there is no fixed effective source for applying sciences university teachers. Therefore, the applied sciences university course is only scattered in the experience of schools, enterprises, and society, rather than the unique system of applied sciences universities course system. Without a first-rate teacher, it is difficult to create a first-class curriculum. To build an applied sciences university course, we must first build a professional applied sciences university teacher team.

\subsection{Enterprises Play an Insufficient Role in Curriculum Construction}

Presently the curriculum construction of vocational colleges mostly takes the school as the main body and the government as the leading factor. In the process of curriculum construction, the students' survival ability is not given enough attention, so that the students cultivated have weak viability in the market economy society. In the process of cultivating talents, schools often attach importance to theoretical and moral learning, while ignoring survival learning. This is also the reason why the current ideal employment unit for graduates is government administration, institutions or state-owned enterprises, rather than private enterprises and foreign-funded enterprises. And the pressure of working in private enterprises, foreign-funded enterprises, small and micro enterprises is relatively large. The applied sciences university course should be based on schools and enterprises, and it should let enterprises play a leading role. It is not only to let students learn the technical skills that enterprises need, but also to learn the survival ability of enterprises in the market.

\subsection{Shorting Technologies in the Course Evaluation}

Curriculum construction is the key to governing education according to law. It is necessary to comprehensively strengthen the construction of the curriculum system of applied sciences universities, which can strengthen the monitoring of the curriculum links to ensure that each link is designed, developed, implemented and evaluated according to requirements. The course evaluation work is the "viewing 
the mirror" part of the course. It needs to see if the course is gone and measure the accuracy of the work. At present, the curriculum reform in China is precisely because there is no strict control of the course evaluation, and the phenomenon of large scale and uneven quality will appear. In the course of construction, the applied sciences university course should implement the whole process of monitoring and evaluation, especially the use of big data technology, comprehensively and systematically evaluate the process and results of the course implementation, and play the role of the course evaluation link to realize the system development effect of "design $\rightarrow$ development $\rightarrow$ implementation $\rightarrow$ evaluation" in the course construction.

\subsection{New Ideas and Methods for the Courses of Applied Sciences University Need to Be Updated and Strengthened}

Klau, Executive Chairman of the World Economic Forum, firmly believes that the fourth industrial revolution will have the same powerful, far-reaching and historic influence as the previous three industrial revolutions, but the fourth industrial revolution put forward new and high demands on global and national leadership and judgment, for the opportunities and challenges brought about by the fourth industrial revolution, the world lacks a consistent, positive and universal concepts. [6] Therefore, the Applied Sciences University course is not a derivative of the Industrial 4.0 era, but a co-biological of Industry 4.0, which requires the full support of the concepts, management, technology, equipment, and industry of Industry 4.0. This puts higher requirements on the design, development, implementation and evaluation of the applied sciences university curriculum in terms of informatization and intelligence. It requires the curriculum stakeholders to have the power and ability to open up a new era. To create a modern vocational education curriculum 4.0 that meets Industry 4.0 .

\section{Practice of Curriculum Reformation in Tianjin Sino-German University of Applied Sciences in the Big Data Era}

"Data science is the science of data. Its goal is to explain processes and objects through the available data. The explanation is expected to be objective and accurate enough to make predictions. The ultimate goal of the explanations is to make informed decisions based on the knowledge extracted from the underlying data."[7] The "Taylor Principle" proposed by the famous American educator, curriculum theory expert and evaluation theory expert Tyler in the book "Basic Principles of Curriculum and Instruction" is recognized as the most perfect and clearest explanation of the principles of curriculum development. And the principle is based on the "technical rationality" and the values of the work process. The University of Applied Sciences is a product of an industrialized society or a new industrialized society. Building the applied sciences university curriculum system based on the "Taylor principle" is not only operability, but also deeply conforms to the value rationality and regularity of industrial technology. Based on the "Taylor Principle", the applied sciences university curriculum reform should combine the working process systematic curriculum theory, draw on the big data concept and technology, and applied sciences university curriculum design, curriculum development, curriculum implementation and curriculum evaluation reform based on the background of informatization and intelligence. The specific process is shown in Figure 1.

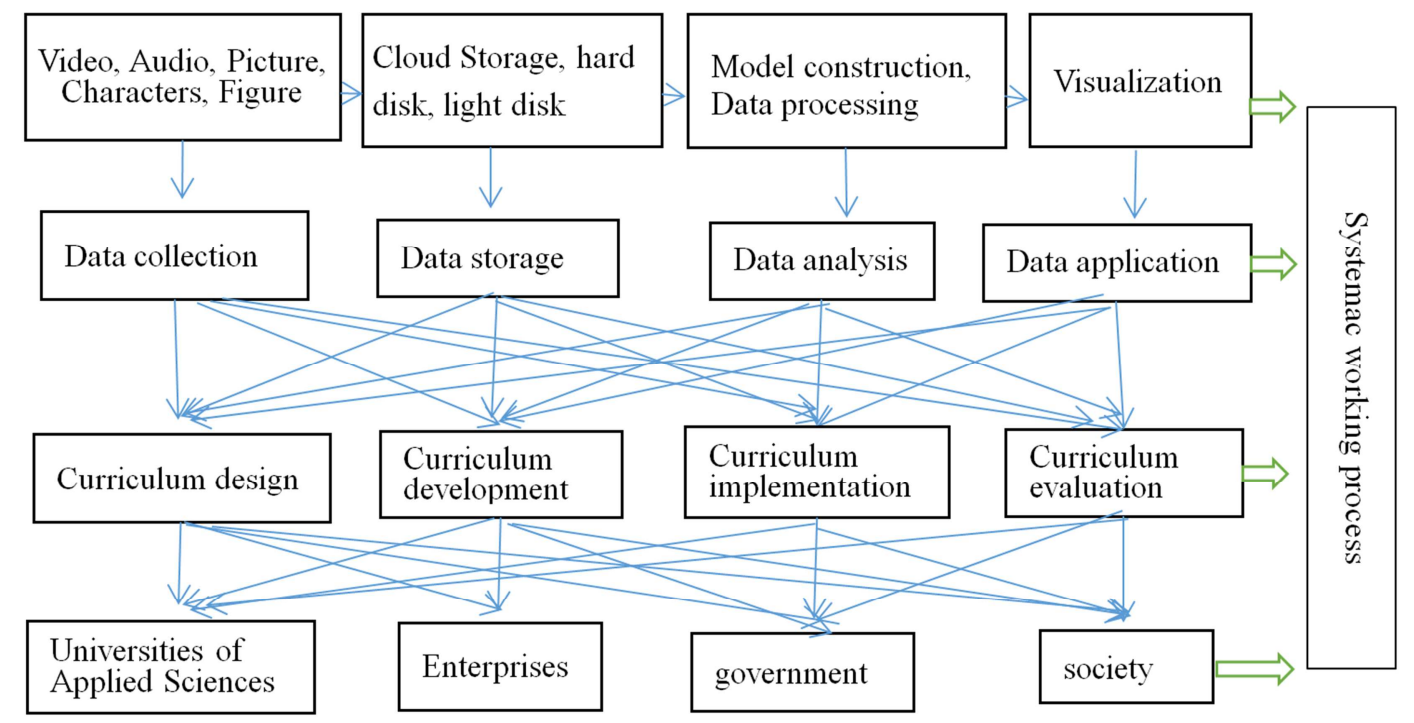

Figure 1. The development process of curriculum reformation in the university of applied sciences.

\subsection{Curriculum Design}

The course of change and development will be accompanied by changes in the concept and meaning of the new curriculum. For example, the American scholar David proposed four concepts of the curriculum, including the elimination of ignorance, the provision of knowledge to 
manage human society and nature, the promotion of human kindness and the protection of students from the upper classes. [8] The overall goal of the design of the University of Applied Sciences is to train the applied and technical skills of the regional economic and social development, especially the front-line talents. But "any single source of information is not enough to provide the basis for a school to make comprehensive and sensible decisions for educational goals. [9]" Therefore, the curriculum design should consider the comprehensive factors, including the learner itself, regional economic society, industrial technology links, curriculum experts, etc., And screen educational goals through the philosophical and learning psychology, and through the big data technology, a more accurate understanding of the data and information in the work process, for a clearer curriculum design.

At present, most of the applied sciences universities implement applied sciences education at the undergraduate level. Teachers need to understand the students' physical and mental health, direct social relations (Relationship between loved ones, friends, acquaintances), social-civil relations (Life in school, community), consumer life, study life, leisure life, hobbies, academic foundation and other data, construct a student feature model, and form a visual student model through information technology to find out the space for curriculum design.

Tianjin is a international advanced manufacturing research and development base with developed industries and complete categories. It has built eight emerging pillar industries such as aerospace, petrochemical, equipment manufacturing, electronic information, biomedicine, new energy, new materials and national defense industry. 150 of the world's top 500 companies have established branches and offices in Tianjin. These local enterprises are a huge database and a concentrated expression of industrial big data. The course building team needs to use different technical means to collect data on local industrial development through a database of local industry and informatization authorities. Through data mining techniques such as mathematical modeling, the paper analyzes the data that has great value for local industrial development, and then uses data visualization technology to describe the structure of local industrial development. The industrial big data constructed by big data technology provides a scientific basis for the applied sciences university curriculum design, which is conducive to integrating the applied sciences university curriculum into the regional economic society development process and the front-line work of the enterprise to realize the coordinated development of the two.

Curriculum design refers to the way we conceptualize the curriculum and arrange its major components (subject matter or content, instructional methods and materials, learner experiences or activities) to provide direction and guidance as we develop the curriculum. [10] Applied Sciences University curriculum design is a specialized job that requires experts in all aspects. These experts should deal with data from the government, universities, enterprises, and industry associations, combining the laws of industrial development, the rules of student learning, and the rules of education and teaching. According to the actual work process, the conflict concept and the content that does not conform to the student's learning rules are revised to ensure that students have no conceptual conflicts during the learning process and reduce learning disabilities. The applied sciences university curriculum design description can be procedural, accurate, and measurable.

\subsection{Curriculum Development}

Curriculum development is to choose the learning experience that can achieve the training objectives, and select the application-based technical skills needed for regional economic society development, especially information technology and intelligent technology. With the help of big data technology, collect data in the course of course development, conduct data analysis, mine useful information, monitor the progress of course development in real time, and strive to achieve the cutting-edge and full coverage of the development course. The applied sciences university course development is broken down into the following steps:

\subsubsection{Form a Course Development Team}

The importance of identifying a strong expert panel that is comprised of educators with content and teaching expertise is essential to ensure a quality alignment and to avoid some of the issues raised by researchers. [11] The current curriculum teams are mostly school-led curriculum teams, and there are also individual curriculum teams led by local education administrations or industry associations. The course team must be diverse in order to meet the curriculum design requirements. The Applied Sciences University course team must first include the school teacher because the teacher is the direct implementer of the course; Followed by technical skills experts who understand the practical effectiveness of technical skills in the workplace and can select the application-based technical skills needed for regional economic society development; Once again, the principal, the strong support of the principal and the full promotion can guarantee the steady development of the curriculum; Finally, big data experts, they closely link all aspects of strength to form a curriculum building team database.

\subsubsection{Generate and Refine the Course Objectives, and Draw the "Course Goal Tree" by Drawing a "Work Process Diagram"}

The application-oriented and technical-skilled talents required for regional economic society development are the general objectives of the applied sciences university curriculum. The process of curriculum development is the process of decomposing the overall goal, the process of decomposing work, and the process of collecting big data for curriculum development. The first is to break down into a large category of different application technology skills by trade or industry, and secondly to break down into different types of work in the large category, and then decompose the 
jobs in the work, and finally decompose into each specific technical action, and sets standards for each technical action, position, job type, and industry skill compliance. Through the decomposition, draw a "technical skills talent training target decomposition tree" to form a growth technology skills talent growth chart.

\subsubsection{Select Course Content}

Use the big data technology to find the latest technical skills program according to the "Technology Skills Training Target Decomposition Tree"; the content of the courses found in the enterprise must be large and complex, and cannot be directly used as a school curriculum. Therefore, it is necessary to organize the collected course contents and reorganize the course structure according to the difficulty and importance of technical skills; the next step is to screen the course content according to the standard. First of all, the course content enables students to grow considerably in terms of mind and economy through the course of study; Second is interest, the choice of curriculum must pay attention to the interests of students, because knowledge and skills are valuable when students are interested; Once again, integration, technical skills in the practice process are some redundant actions or links that need to be removed in the course selection; Finally, the difficulty is appropriate, because the course is a course for most students, and if it is too difficult, it will lead to the implementation of the course.

\subsubsection{Choose a Course Environment}

The implementation of the University of Applied Sciences Course must have a large number of training workshops, laboratories, training bases, etc., because it trains applied and technical skills, all professional courses will have training and experimental requirements. Therefore, draw the "Course Objective Tree" to select the teaching environment for the course development of big data visualization. It can be used in schools or enterprises to ensure the space of the teaching environment is adapted, the quantity is sufficient, the operation is clear, the temperature is suitable, and the economy is applicable.

\subsection{Curriculum Implementation}

The current and future working life is missing people with, instead of memorized lists of information in their heads, readiness to adapt to the change, learn the skills required for the job at each time and further develop operations in a sustainable manner. [12] Curriculum implementation is an evolutionary process and a crucial stage in curriculum construction. According to American scholars Wiles and Bondi, more than $90 \%$ of new curriculum development projects have failed during course implementation because educators lack the skills and knowledge to implement a new curriculum. Curriculum implementation is a process of gradual, communication, and persistence. It will encounter changes in plans, internal conflicts, etc., and may also be resisted. For example, in the implementation process, teachers lack sense of ownership, gain, increase work burden, lack of policy support, insecurity, boredom, and change.

The applied sciences university course is more integrated into the industry enterprises, the regional economic society, and subverts the concept of the previous higher vocational college curriculum, so that the course content, methods, evaluation and other aspects are different from the past, the MOOC, micro-class, AR, VR, cloud teaching materials, mobile learning platform, etc. are fully entered into the teaching process. The process of course implementation is also a process of big data collection, storage, analysis, and application. In the course of course implementation, the first step is to use the big data results in curriculum design and curriculum development. On this basis, the preparatory work for the course implementation is completed, the student's learning process is concerned, and the students' original knowledge, learning needs, learning ability, course aspirations and other data are collected to form an image that is visualized during the student's learning process; Secondly, it pays attention to the teacher's teaching process, collects the teacher's knowledge structure, teaching desire and teaching ability data, and forms a visual image of the teacher's teaching; Then, collect data on the migration of course knowledge and collect data that will be of value in the course teaching. Through the data implemented in these courses, choose to use teaching methods such as online teaching, virtual teaching or practical teaching to ensure the accuracy and effectiveness of the curriculum implementation.

\subsection{Curriculum Evaluation}

Curriculum evaluation is an indispensable part of curriculum construction. It determines the value of the curriculum plan to achieve the goal of talent training. It is necessary to judge the extent to which the curriculum achieves the curriculum objectives and points out the advantages and disadvantages of the curriculum. Summative assessment is concerned with determining whether students have mastered particular elements of the curriculum. [13] People have always questioned the fairness of their values and the validity of evaluation data. Big data technology can concentrate all the data of the course for analysis, which is a pure and objective method of course evaluation.

Firstly, the applied sciences university curriculum evaluation must first evaluate the course knowledge and skills, which requires the collection of industrial technical data, job skills data. Applied sciences university course evaluation based on ensuring students' morality and legal evaluation, it is necessary to highlight the applicability and technical skills evaluation of the course, which poses a challenge to the way of curriculum evaluation, and the big data evaluation technology can well solve this problem.

Secondly, the applied sciences university curriculum evaluation should collect and analyze the student's curriculum learning data, and strengthen the formative evaluation of technical skills. Understand the starting point, process, and results of student learning by storing, mining, and visualizing student learning data. And through accurate 
teaching evaluation, we can understand the learning situation of each student, evaluate all students, and give each student a unique evaluation result. Through this evaluation result, students can have a clearer understanding of their own learning, and thus determine the content and direction of the next step of learning.

Thirdly, the applied sciences university curriculum evaluation should pay attention to the data of teachers designing, developing and implementing courses. Teachers are the main implementers of the curriculum, and teaching evaluation must pay attention to the situation of teachers. Through the big data technology, collect teachers in curriculum design, curriculum development, curriculum implementation, and even curriculum evaluation, strengthen the analysis of data, visualize the data, and give relevant recommendations based on the evaluation results. Through such a course evaluation, teachers can find out where they are lacking, so that they can carry out learning and further training in a targeted manner, and enhance the ability to implement the curriculum.

Finally, data is the best evidence and a silent language. With the help of big data technology, teaching evaluation can overcome the defects of subjective evaluation, and even evaluate the teaching evaluation itself; By collecting all the evaluation data about the course, comparing the curriculum design model, the curriculum development model and the curriculum implementation model, we find the advantages and disadvantages of the curriculum work and accurately evaluate the curriculum.

The four modules of the applied sciences university curriculum practice are like the four locomotives on the "Course Round Track". Any problem with one locomotive will affect the operation of the entire track. Big data technology is the monitoring and control system of the entire curriculum practice. By collecting the data of course design, development, implementation and evaluation, the value of the data is mined, and the curriculum implementation is provided with comprehensive monitoring to improve the accuracy and effectiveness of the course, and improve the quality and level of talent development.

\section{Conclusion}

Big data is the most important resource in the modern society, it brings more opportunities than challenges to us. China's Ministry of Education has issued several documents to compromise Internet and education, and constructed MOOC of China's universities. Since curriculum is the primary vehicle for achieving the goals and objectives of a school, a focus on curriculum planning and development is naturally a top priority of education reform. [14] The curriculum reformation with big data technology in China, example as Tianjin Sino-German university of applied sciences, has make a good differences in higher education and strengthen the university's work. Nevertheless, the big data technologies is immaturity, and big data talent is insufficient, the curriculum reform has not solved all the problems and questions in education of applied science. On the basis of curriculum reform using big data technologies, we can reach the following conclusion.

The first and most important thing is we have done the work that reforming curriculum with big data technologies, all the teacher take in part of this program get a good knowledge of big data technologies and course, and we took one step forward in the new realm. Tianjin Sino-German University of applied sciences as the first new type university to explore new higher education models to nurse two kinds of qualified personnel: technical type and skillful type. Dual curriculum system is a new higher education course model that university of applied sciences adopts big data technologies constructed.

Secondly, big data technology is complicated and immature, though we did a lot of work, but we still cannot get the perfect output. On the one hand, we cannot take curriculum as a work which needs one or two years, it needs four years or more to get the practical experiences, the working group evaluate the process and results of curriculum reform to optimize the course structure. On the other hand, the teacher and student are still accustomed to the traditional courses, short of computer and other advanced electric equipment, so it is a complex and difficult task to make teacher and student adapt to the change of curriculum.

Thirdly, there is little doubt that higher education is facing unprecedented change-from evolving expectations for student outcomes, rapidly developing technologies, changing student demographics, to pressures and shifts in funding. [15] the development of internet of things, artificial intelligence, machine learning, cloud computing, and the construction of the data infrastructure have made the application of big data technology which is based on them be applied in different fields of people's life with surprising speed, especially in higher education course. The applied sciences university curriculum system construction must be based on the modern vocational education system, with the help of big data technology, it is open, innovative, practical and systematic, highlighting information, intelligence and datafication, and forming a unique curriculum theory system and curriculum practice system. In this way, it is possible to cultivate the application-oriented and technical-skilled talents needed for regional economic society development, and to develop a University of Applied Sciences with Chinese characteristics and world-class status.

\section{Acknowledgements}

"This research was supported by Humanities and Social Sciences Foundation Project in the Ministry of Education (16YJA880052); Teaching Reform Research and Practice Project in the Tianjin Sino-German University of Applied Sciences (ZDJY2019-24); Humanities and Social Sciences Foundation Project in the Tianjin Sino-German University of Applied Sciences (ZDKT2018-029). 


\section{References}

[1] The State Council. the Outline for the Promotion of Big Data Development. http://www.gov.cn/zhengce/content/2015-09/05/content_1013 7.htm.

[2] Ben Kei Daniel, Big Data and Learning Analytics in Higher Education: Current Theory and Practice, Springer International Publishing Switzerland, 2017, pp. 22.

[3] Dilly Fung, A Connected Curriculum for Higher Education, UCL Press, 2017, pp. 8.

[4] Tao Yongqin, The Application Research of the Knowledge Evolution for School-Enterprise Collaborative Model under the Big Data Environment. Hans Journal of Data Mining, 2015, pp. 8-15.

[5] Ayesha Bashiruddin, Teacher Development and Teacher Education in Developing Countries, Macmillan Publishers Ltd, 2018, pp. 3.

[6] Schwab K. Fourth Industrial Revolution. New York: Crown Business, 2017. pp. 4.

[7] A. Said and V. Torra (eds.), Data Science in Practice, Studies in Big Data. Springer International Publishing AG, 2019. pp. 1.

[8] Orr D W. Earth in mind: On education, environment, and the human prospect. Washington DC: Island Press, 2004, pp. 125.

[9] Ralph W. Tyler, Basic Principles of Curriculum and Instruction. Beijing China Light Industry Press, 2016, pp. 5.

[10] Allan C. Ornstein, Francis P. Hunkins, Curriculum: Foundations, PrinciPles, and issues, Pearson Education Limited, 2018, pp. 31.

[11] Kristen R. Stephens, Frances A. Karnes, Introduction to Curriculum Design in Gifted Education, Prufrock Press, 2016. pp. 57.

[12] Mirva Virtanen. Education and its structures must be reformed new publication tells us how to do it. https: //www. tuas. fi/en/articles/297/education-and-its-structures-must-be-reform ed-new-publication-tells-us-how-do-it/.

[13] Sandra Leaton Gray, David Scott, Peeter Mehisto, Curriculum Reform in the European Schools, Palgrave Macmillan, 2018, pp. 105.

[14] Curriculum Planning: Integrating Multiculturalism, Constructivism, and Education Reform, Springer International Publishing, pp. 7.

[15] Rhiannon D. Williams, Amy Lee, Internationalizing Higher Education: Critical Collaborations across the Curriculum, Sense Publishers, 2015, pp. 3. 